\title{
EFFECT OF THERMO-CYCLING ON RETENTIVE FORCES OF DIFFERENT ESTHETIC THERMOPLASTIC CLASP MATERIALS FOR REMOVABLE PARTIAL DENTURE. (IN-VITRO COMPARATIVE STUDY)
}

\author{
Eman Husseiny Mohammed* and Mohammed Ezzat El Sayed ${ }^{* *}$
}

\begin{abstract}
Purpose: The objective of this in vitro study was to evaluate the effect of thermocycling on retentive forces of different esthetic thermoplastic partial denture clasp materials including, polyoxymethylene (Acetal), polyetheretherketon (PEEK) and monomer free semi-rigid microcrystalline polymer (karadent).
\end{abstract}

Material and methods: 2 Testing models with 2 natural premolar teeth used to test the retentive force of three types of esthetic thermoplastic clasps $(\mathrm{N}=6)$ Acetal, PEEK and karadent. After Thermo-cycling, the retention force of the clasps was measured at the same cross head speed. The data were collected, tabulated and a statistically analyzed using SPSS v26, Kruskal Wallis was used for comparing quantitative non-parametric data of more than two different groups, followed by post-hoc Dunkan's while Wilcoxon signed rank was used to compare quantitative non-parametric data of two related groups.

Results: PEEK group has recorded a high statistically significant difference in retention force mean values prior to thermo-cycling, P-value $\leq 0.001$. Following thermo-cycling, reduced retention force mean values were found for all groups with non-significant difference between the groups and a significant difference within each group. For the percentage of changes, there was a significant difference between the groups with the least percentage of changes in the Acetal clasp group. $\mathrm{p} \leq 0.05$.

Conclusion: Within the limitations of this study, it was found that the thermoplastic resin clasps-showed a decreased retention values when exposed to thermo- cycling ( 2000 cycle) between (5 C-55 C) 30 seconds with significantly lower percentage of change for the Acetal than Peek and karadent esthetic clasp materials.

KEYWORDS: Denture clasp, Polyetheretherketon, Thermocycling exposure, esthetic thermoplastic clasps.

* Lecturer at Prosthodontic Department, Faculty of Oral and Dental Medicine, Zagazig University.

** Associate Professor, Removable Prosthodontics, Faculty of Dentistry Suez Canal University. 


\section{INTRODUCTION}

Although removable partial dentures (RPDs) are preferred options for the restoration of many situations that involve partial tooth loss, some patients are no longer satisfied with a removable partial denture (RPD), specifically when it is not stable during mastication. As a result, sufficient retention of RPDs is regarded as one of the essential factors that have an effect on the clinical success of the RPDs. ${ }^{(1)}$ The mechanical properties of RPD retainers rely on the material composition as Titanium, gold, Nickel/Chromium and Cobalt/Chromium (Co-Cr) alloys. ${ }^{(2-5)}$

Most researches on clasp materials and designs were carried out as in-vitro investigations. ${ }^{(6)}$ Some of the studies of clasps had been performed under a constant load ${ }^{(7-14)}$ or a constant displacement. ${ }^{(14-19)}$

Researchers considered the long-term effectiveness of the clasps and the possible impact of the clasp might have on the abutment teeth. ${ }^{(17-19)} \mathrm{A}$ clasp arm design that produces less stresses is very important for the predictable long-term use of RPD. Three factors include clasp material, clasp form, and the amount of undercut affect the design of a clasp arm. ${ }^{(12)}$

An essential esthetic problem with PRDs is the visualization of the clasp assemblies. Many strategies have been used to overcome the esthetic issues such as etching the clasp arm and coating it with a layer of tooth-colored resin, using lingual retention design, or proximal undercuts (also known as rotational path insertion. (20-22) Thermoplastic resin clasps were introduced to overcome the problem of the poor esthetic of $\mathrm{CoCr}$ clasps. Therefore, Polyoxymethylene (POM), also known as Acetal, has been used for the construction of RPD retaining and supporting components. ${ }^{(23-25)}$

Polyoxymethylene (POM) additionally recognized as Acetal resin, an injection-molded resin has been introduced as an alternative to traditional polymethylmethacrylate PMMA. POM is formed through the polymerization of formaldehyde. The homopolymer, polyoxymethylene is a chain of alternating methyl groups linked by an oxygen molecule. It has a fairly proportional limit with little viscous flow enabling it to behave elastically over a great enough range to be used as a material for clasp construction. ${ }^{(26)}$

It has been concluded that the non-metal Acetal resin retainer displays superior mechanical properties than valplast and $\mathrm{CoCr}$ clasps. ${ }^{(27)}$

Polyetheretherketon (PEEK) is a polyaryletherketone (PAEK) polymer, it is a fairly new family of high-temperature thermoplastic polymers. It is composed of an aromatic backbone molecular chain connected to each other via ketone and ether functional groups. In medicine PAEK has been verified to be an excellent substitute for titanium in orthopedic applications and it has been used as a temporary implant abutment in dentistry. ${ }^{(28,29)}$

The microcrystalline polymer as a thermoplastic resin (Karadent by TCS, NC, USA) introduces several advantages over traditional denture base materials, including high aesthetic, maximum strength and durability, no volume shrinkage, exceptional fit, minimal water absorption, lower residual monomer content so it acts as alternatives to PMMA in allergic patients, hence it can be used as a thermoplastic esthetic clasp material. ${ }^{\left({ }^{30}\right)}$

During clinical service, prosthetic restorations are commonly under prerequisites of thermal changes and loads in the oral cavity, which can cause damage to the surface and mechanical properties of the materials. Changes in temperatures in the oral cavity are caused by daily diet, and open-mouth respiration, which have a long-term negative effect in promoting crack propagation, thus changing the physical properties of the material. ${ }^{(31-33)}$ Due to these factors, dental materials should be tested under conditions similar to those found in the oral cavity. Thermal cycling is an in vitro process that is used to simulate in vivo events. ${ }^{(34)}$ 
Several investigations ${ }^{(35-38)}$ have studied the effect of thermo-cycling on different mechanical properties of thermoplastic resin materials including surface microroughness ${ }^{35}$, flextural strength $^{36}$ and impact strength ${ }^{(37,38)}$ but, nowadays, rare investigations have evaluated the effect of thermocycling on the retentive forces of different esthetic thermoplastic clasp materials for removable partial dentures which is important for the long term success of the prostheses. The aim of this study was to compare effect of thermo-cycling on the retentive forces of different esthetic thermoplastic clasp materials including Acetal, PEEK and karadent.

\section{Null hypothesis}

Null hypothesis of the study was that there would be no significant differences between the three tested materials as regard to their retention forces before and after thermo-cycling

\section{MATERIALS AND METHODS}

The calculated sample size of the study was 6 esthetic clasp materials in each of the three group (total of 18 clasps) at 5\% level of significance and $80 \%$ power, using the following formula:

$$
\begin{aligned}
& \mathrm{N}=(\mathrm{Z} \alpha / 2+\mathrm{Z} \beta) 2 * 2 * \sigma 2 / \mathrm{d} 2, \\
& \mathrm{Z} 1-\alpha / 2=1.96 \\
& \mathrm{Z} 1-\beta=0.842
\end{aligned}
$$

Mean retention in peek group at baseline $=39.19$

$$
\text { Mean retention in peek group after }=15.19 \text {. }
$$

$\delta=$ Expected difference to be detected between the two studied groups regarding retention (24)

$\alpha=$ Level of acceptability of a false positive result (level of significance $=0.05$ )

$\beta=$ Level of acceptability of a false negative result $(0.20)$

$1-\beta=\operatorname{power}(0.80)$.

\section{Testing model fabrication and study design}

For this study 2 natural maxillary first premolars were used for the construction of 2 testing models to carry the retentive force measurements.

The inclusion criteria for premolar selection were: upper first premolars without any reconstruction or existing caries and similar crown dimensions. In turn, all first premolars larger or smaller than the chosen and teeth with caries and / or reconstructions were excluded from the study. This was an experimental in-vitro research not a human one and waived of consent.

2 Testing models were made by placing 2 natural premolar teeth inside acrylic blocks to test retentive force of three types of esthetic thermoplastic clasps Polyoxymethylene (Acetal), Polyetheretherketon (PEEK), and thermoplastic monomer free semi rigid microcrystalline polymer (karadent). Laboratory custom-made copper castings (30 mm long, $15 \mathrm{~mm}$ wide, and $10 \mathrm{~mm}$ high) were used to make the testing models. The testing models were made of rectangular acrylic blocks (Stellon, DeguDent Gmbh, and England). The natural teeth were embedded vertically to their cemento-enamel junction (Fig 1 A). ${ }^{(40)}$

A special movable jig was constructed to fix the testing model perpendicular to the pulling out machine. A cavity was created at the center of the superior surface to receive the testing model.The base of the acrylic block and its superior surface was made parallel to the surveyor table (Ney Surveyor; Dentsply, New York, New York, USA). (Fig 1, B).

For the two crown models, 18 clasps were fabricated so that 9 clasps were constructed on each model (clasp undercuts of $0.5 \mathrm{~mm}, 1.5 \mathrm{~mm}$ thickness). The clasps were divided according to esthetic thermoplastic resin materials (Acetal, PEEK, karadent) into three groups ( $\mathrm{N}=6$ clasps for each group. By using Instron universal testing machine ((Instron model 3345 England) and the data was recorded using computer software Bluehill version 3.3). The retentive force of each clasp within the three groups 
was measured before thermo-cycling, each clasp was pulled out 10 times with a crosshead speed of $10 \mathrm{~mm} / \mathrm{min}$, and the force required to pull each clasp was measured. All groups of clasps were then exposed to thermal cycling (2000 cycle) between $\left(5^{\circ} \mathrm{C}-55^{\circ} \mathrm{C}\right)$ for 30 seconds. After thermo-cycling, the testing models were fixed to the same position of instron and the retention force of the clasps was measured at the same cross head speed.

\section{Abutment teeth preparation}

The models had been surveyed at zero tilt position; then the abutment of the testing models was surveyed to make sure of sufficient undercut, and the undercut depth was measured with the aid of the 0.02 inch undercut. The path of insertion was then recorded with the aid of the surveyor. Occlusal rests seats were prepared with buccolingual and mesiodistal dimensions $2.5 \mathrm{~mm} \times 2.5 \mathrm{~mm}$ and depth $1.5 \mathrm{~mm}$ were prepared using round diamond no. 6 . The rest seat preparation was outlined in pencil and examined by digital caliper to make certain of the size. When necessary, the palatal surface was reshaped using a stone with low-speed hand piece for lowering the height of contour to provide an ideal balance (reciprocation) between the two arms of the clasps. To obtain standardization, a milling machine (AF 30, milling machine, Switzerland) was used

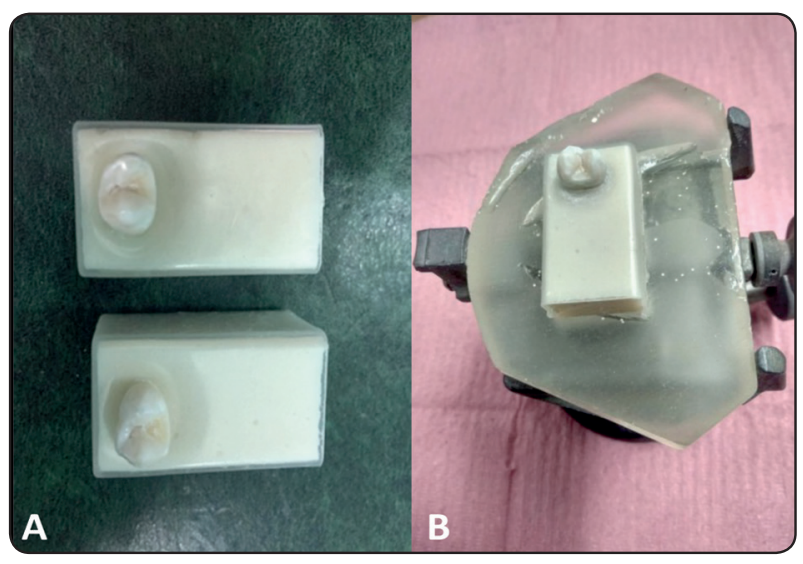

Fig. (1) (A, testing models with the natural teeth embedded to the cemento-enamel junction, B, a movable jig to hold the testing model.) to prepare a parallel guiding plane approximately $2 \mathrm{~mm}$ along occlusal-gingival direction on the proximal surface. (Fig2A, B)

\section{Test Model preparation and duplication}

Following the abutment tooth preparation and for the Peek clasps fabrication, A duplicate from each testing model was poured in extra hard stone (type IV, Elite Rock; Zhermack). The stone models were scanned using CAM software (Dof Swing, Dof, C0 South Korea) to create virtual models obtaining a standard tessellation language (STL) file format. Then imported to the CAD soft-ware, used to start the design process. The virtual models were digitally surveyed to delineate the survey line, determine the most suitable path of insertion, and block out all the undesirable undercuts. The clasp resin pattern assembly and the distal extension area were digitally designed on the virtual casts that resembles ready-made Aker clasp pattern used for the construction of acetal and karadent groups. Milling machine (Arum ,Yuseong-gu Co, Daejeon, South Korea) was then used to produce indirect rapid prototyping (RP) (resin 3D printing pattern combined with thermopress technique for Peek clasps). So that three PMMA patterns were produced for each testing model. ${ }^{(40)}$ (Fig. 3A,B)

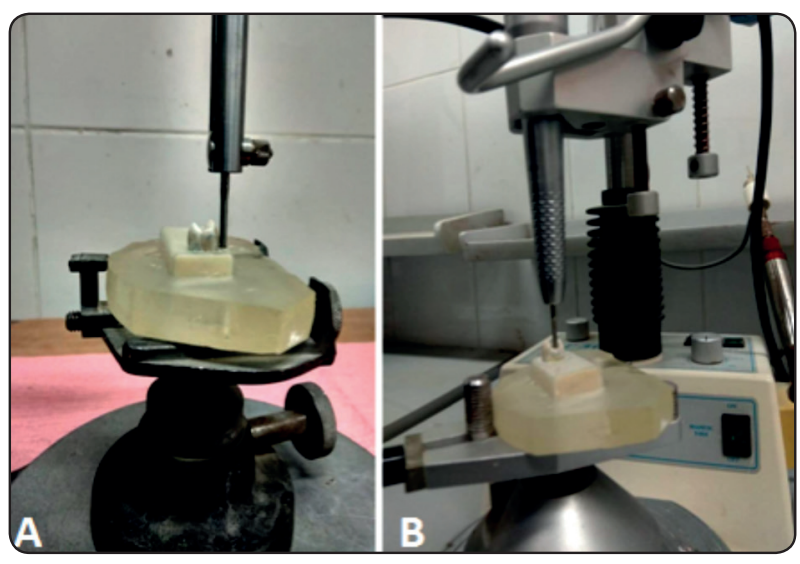

Fig. (2) (A, B) surveying and preparation of the abutment teeth. 
For the fabrication of Acetal and Karadent clasps, on the testing model ,a ledge of wax was positioned on the buccal surface to standardize the locations and lengths of the retentive arms. On the palatal surface, a piece of wax, rectangular in shape, was positioned as a reference to standardize the locations and lengths of the reciprocal arms (Fig4A). To eliminate the effect of proximal undercuts on the retention force, a softened wax was used for the blockage of the unwanted undercuts, then trimmed with the help of the wax trimmer of dental surveyor. A condensation silicon impression material (Expando-Rock; Bredent, Germany) in a stock tray was used to duplicate each model. Each impression was poured with Type IV dental stone (GC Fujirock $\mathrm{EP}, \mathrm{GC}$ ), to make refractory casts. Each impression was poured 6 times to obtain 12 stone models, used for the Acetal and karadent esthetic clasps fabrication (Fig. 4B). A small piece of wax (0.7 $\mathrm{mm}$ thickness, $20 \mathrm{~mm}$ length and $5 \mathrm{~mm}$ width), was attached to the superior surface of the model, and $2 \mathrm{~mm}$ from the proximal tooth surface to provide a framework stopper (Fig4C). ${ }^{(41)}$ Standard preformed half round Aker clasp wax patterns (1.5mm) (ready made Aker clasp pattern; Bego, Germany) with occlusal rest, retentive arm, reciprocal arm and minor connector were then adapted on the refractory casts with one clasp pattern for each cast. A vertical sprue (20 $\mathrm{mm}$ in length and $3 \mathrm{~mm}$ in diameter) was connected to the prepared wax plate at the distal saddle area, which was used latter on for holding of the clasp assembly in the universal testing machine (Fig4D). ${ }^{(25,27)}$

Regarding the strategy used for esthetic clasp fabrication, there are three researched groups each group consists of 6 clasps $(N=6)$ :

Group 1 Acetal: esthetic thermoplastic Acetal resin clasps (Thermoflex Acetal Resin Densply UK), fabricated using injection molding technique

Group 2 Peek: esthetic thermoplastic Peek clasps fabricated using the indirect additive manufacturing (resin printing combined with PEEK thermopressing using the lost-wax technique).

Group 3 Karadent: esthetic karadent clasps fabricated using injection molding technique.
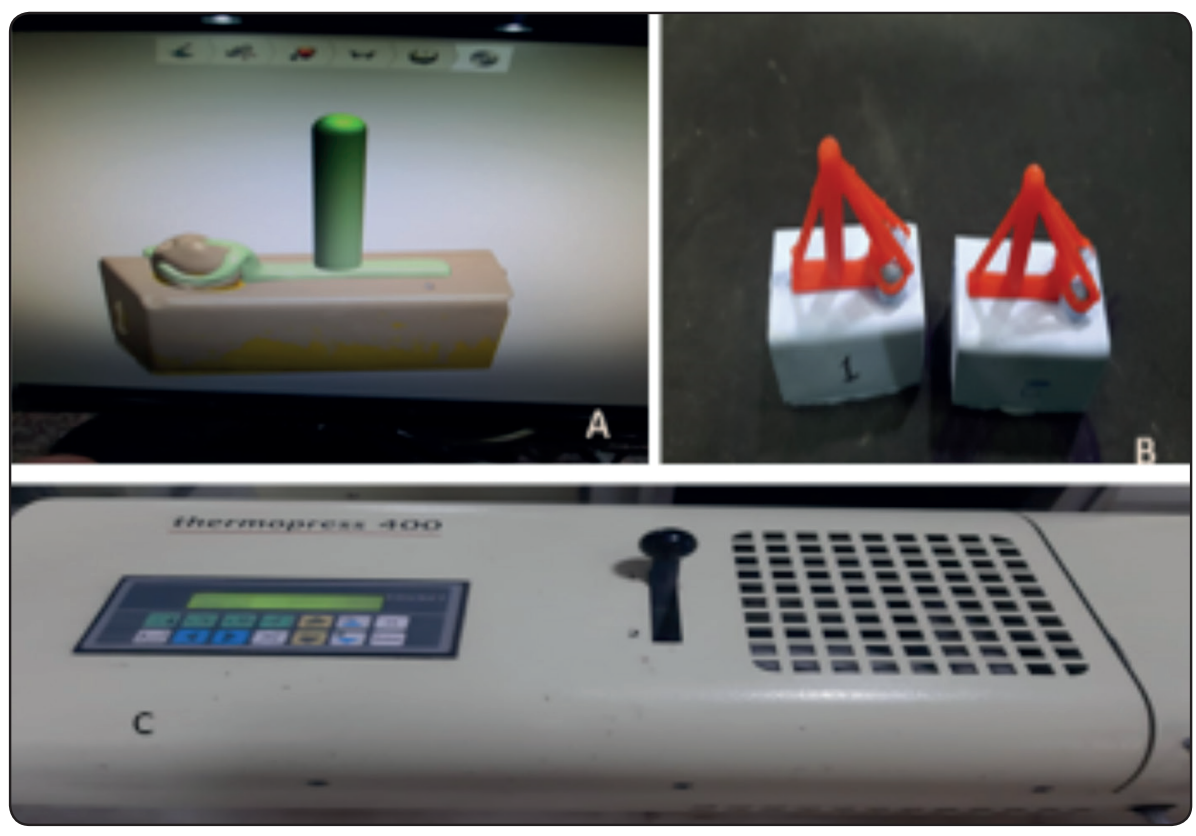

Fig. (3) $(A, B)$ Duplication of the wax pattern and vertical sprue through the use Cad-Cam technology, C) Use of Thermopress injection machine. 


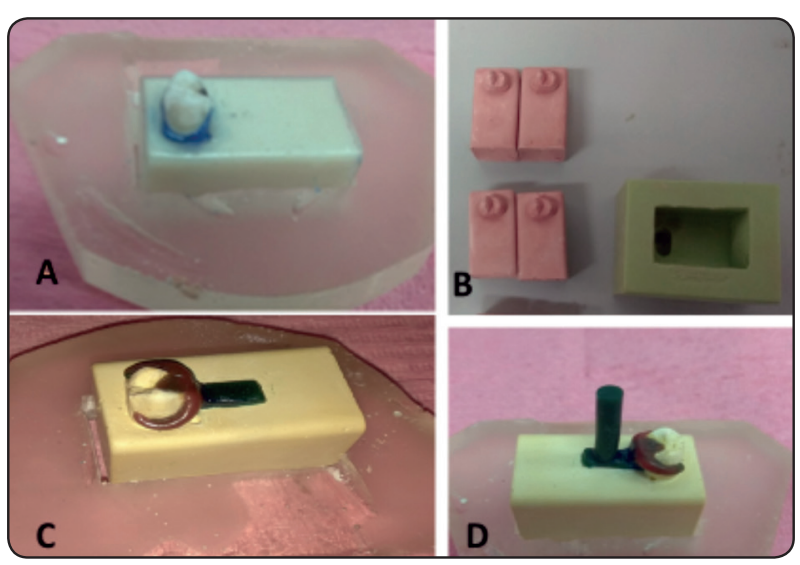

Fig. (4): (A, for ledging of the clasp, B condensation silicone for prepared cast duplication, $\mathrm{C}$ wax pattern of clasp with extended wax as frame work stopper, D attached wax sprue for holding the clasp assembly during testing)

\section{Acetal resin clasp fabrication}

For the acetal resin clasps, the model with its corresponding wax pattern were flasked using Type IV dental stone (Marble Stone; Pressing Dental Srl) and positioned at about $2.5 \mathrm{~cm}$ from the injection opening of the special flask (MuffleType 100; Pressing Dental Srl). A cylinder of the acetal resin was placed into the injection tube, and then the tube was placed in the injection machine (J-100; Pressing Dental Srl). Once in the injection machine, the parameters of the machine were set as follows: the material was kept at $220^{\circ} \mathrm{C}$ (melting temperature) for a preinjection time of $20 \mathrm{~min}$. The temperature was kept at a favorable level of $220^{\circ} \mathrm{C}$ for a post injection time of $3 \mathrm{~min}$, and an injection pressure of 4 bar. $^{(39)}$ At the end of the process, the flask was removed from the initial position, and the clasp was deflasked. The clasp was polished with rubber points (Pressing Dental Srl), and polished using a special polishing paste for acetal and acrylic resins (Universal polish; PressingDental Srl).

\section{Peek clasp fabrication}

The resin pattern was invested in a mold using a special investment (Brevest; Bredent). The mold was heated to $200^{\circ} \mathrm{C}$ for 20 minutes to eliminate the resin and then left to cool. The injection system was preheated according to the manufacturer, and the aluminum cartridge was inserted into the heated chamber once the preheating temperature reached the optimum level. The parameters of the injection were set as follows: preinjection time maintained at $380^{\circ} \mathrm{C}$ (melting temperature) for 20 minutes, post injection time with the temperature maintained at the desired level of $220^{\circ} \mathrm{C}$ for 2 minutes, injection cooling for 60 minutes, and injection pressure of 4 bars. The usual devesting procedure was followed as soon as the mold cooled down. Deflasking, finishing, and polishing of the polished surface of the thermopressed clasps were performed. ${ }^{(42)}$

\section{Karadent clasp fabrication}

Investing the sprue wax patterns of the samples have been done in a vaselinezed aluminum flask.

The opposite half of the flask was built on top of the deposed gypsum surface after investment setting. The wax pattern and sprues were covered by packing the hard dental stone into the upper flask chamber. After the gypsum was set, the flask was immersed in warm water in a thermostatic container. When the wax was boiled and the mold was created. The injection was carried out with an injector (Sabilex, Microinjection machine, Argentina). In the heating cylinder, the injectable material cartridge (Sabilex, Flexi Acetal) was inserted. The preheating operations were then turned on.

The components of the flask had been congregated and installed by screws. The flask was inserted and fixed in the injecting unit's congruent position. After pressing the key on the monitoring panel, squirting began. According to the manufacturer's instructions, the temperature was kept at $280^{\circ} \mathrm{C}$ and the pressure was kept at seven bar for 20 minutes to plasticize the material in the cartridge that would be injected into the flask. After that, the cylinder was moved and the cartridge was separated. The flask was taken out and released, allowed to cool before the investment was removed, the sprue was removed, and finishing and polishing were completed with soft brushes 
and polishing paste.At the end of the process, the flask was removed from the preliminary position, then the clasp was allowed to deflask, polished with rubber points (Pressing Dental Srl). ${ }^{(30)}$

\section{Retentive force testing and Thermocycling}

On the two testing models, every clasp was pulled out ten times before thermo-cycling using Instron universal testing machine at a crosshead speed of $10 \mathrm{~mm} / \mathrm{min}$ (3345 paradigm, England) (Fig 5A) and ten times after thermo-cycling (2000 cycle) equal to two year of function between $\left(5{ }^{\circ} \mathrm{C}-55{ }^{\circ} \mathrm{C}\right)$ for 30 seconds with the aid of a thermos-cycler device (THE-1100 SD Mechatroniks thermos-cycler, Germany) (Fig. 5C).

\section{Statistical analysis}

The resulted data of the retentive force magnitudes before and after thermo-cycling were collected, tabulated and statistical analyzed using SPSS v26. Data were expressed as median \& interquartile range (IQR), Kruskal Wallis was used for comparing quantitative non-parametric data of more than two different groups, followed by post-hoc Dunkan's while Wilcoxon signed rank was used to compare quantitative non-parametric data of two related groups. $\mathrm{P}$ value $\leq 0.05$ was considered statistically significant while $\mathrm{P}$ value $\leq 0.001$ was considered highly statistical significant.

\section{RESULTS}

Tables 1 and 2 Show the mean values for the retention forces (Newton.) for both testing models

A highly significant difference was noticed in retention force mean values between the tested groups prior to thermo-cycling. ( $\mathrm{P}<0.001)$. which was in favor to the PEEK group. Following thermocycling, reduced retention force mean values were found for all groups with no significant difference between the groups and a significant difference for the retention force mean values within each group.

For the percentage of changes of the retention force mean values following thermo-cycling, there was a significant difference between the groups ( $p<0.05$ ) with the least percentage of changes in the acetal clasp material groups.
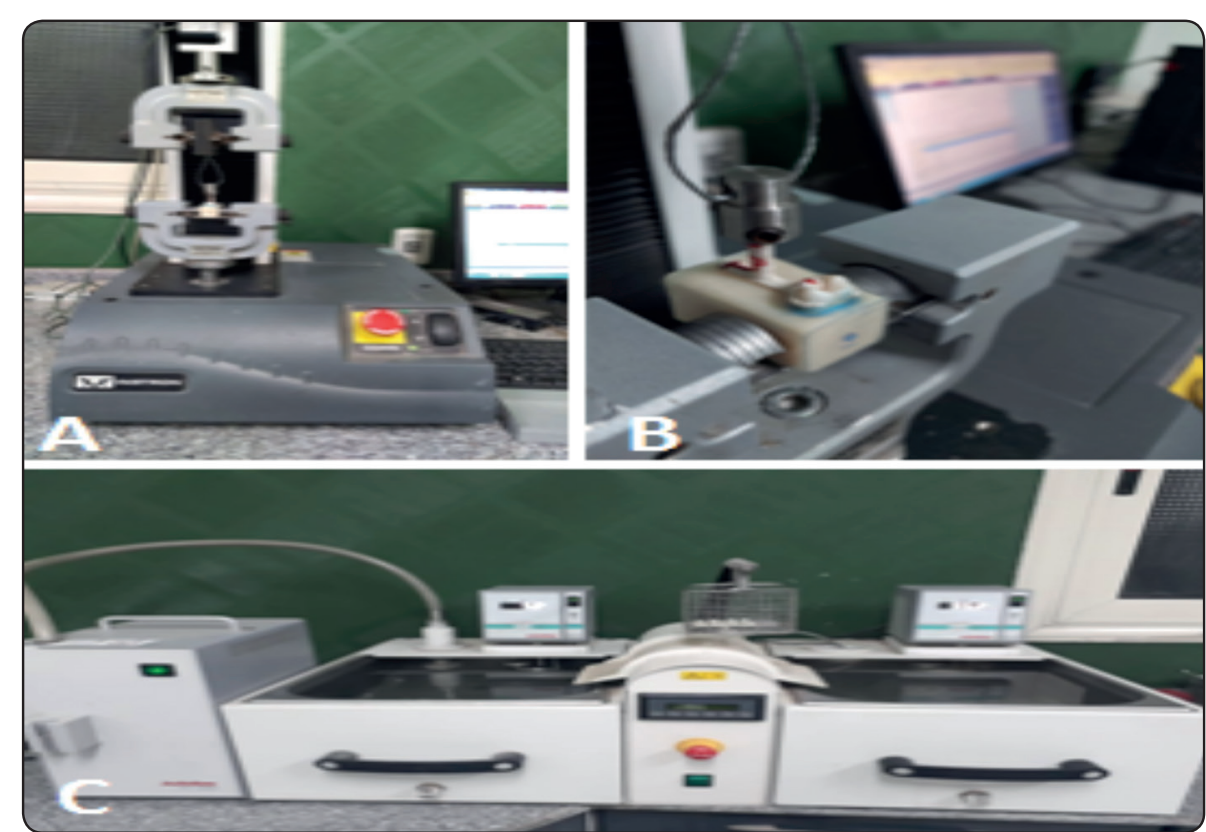

Fig. (5) A Instron Universal Testing machine, B measuring the retentive force, $\mathrm{C}$ thermocycler device 
TABLE (1) :

\begin{tabular}{lccccc}
\hline & \multicolumn{5}{c}{ Testing model 1 } \\
\cline { 2 - 6 } & Group 1 Acetal & Group 2 PEEK & Group 3 Karadent & P \\
\hline Control & $1.61(1.20-1.98)$ & $3.06(2.81-3.61)^{\mathrm{a}}$ & $2.27(1.68-2.31)^{\mathrm{bc}}$ & $<\mathbf{0 . 0 0 1}$ \\
\hline After thermocycling & $.77(.59-.93)^{*}$ & $.97(.73-1.10)^{*}$ & $.53(.30-1.55)^{*}$ & $\mathbf{0 . 0 6}$ \\
\hline Percent of change & $-51.42(-55.98--42.11)$ & $-72.79(-75.87--65.29)^{\mathbf{a}}$ & $-76.98(-87.00--8.73)^{\mathbf{b}}$ & $\mathbf{0 . 0 1}$ \\
\hline
\end{tabular}

Data are expressed as median (IQR), significance when $\leq 0.05$

a: Significance between Group 1 Acetal \& Group 2 PEEK, b: Significance between Group 1 Acetal \& Group 3 Karadent, c: Significance between Group 2 PEEK \& Group 3 Karadent

*: significance between Thermo versus control.

TABLE (2) :

\begin{tabular}{lcccc}
\hline & \multicolumn{5}{c}{ Testing model 2 } & & \\
\cline { 2 - 5 } & Group 1 acetal & Group 2 peek & Group 3 Karadent & P \\
\hline Control & $1.09(.96-1.32)$ & $2.20(2.0-3.01)^{\mathbf{a}}$ & $1.54(1.10-2.20)^{\text {bc }}$ & $<\mathbf{0 . 0 0 1}$ \\
\hline After thermocycling & $.69(.56-.91)^{*}$ & $.52(.34-1.97)^{*}$ & $.51(.49-.58)^{*}$ & $\mathbf{0 . 1 5}$ \\
\hline Percent of change & $-46.22(-59.30--3.87)$ & $-82.96(-84.80--4.97)^{\mathrm{a}}$ & $-67.60(-76.86--54.94)^{\mathbf{b}}$ & $\mathbf{0 . 0 0 9}$ \\
\hline
\end{tabular}

Data are expressed as median (IQR), significance when $\leq 0.05$

a: Significance between Group 1 Acetal \& Group 2 PEEK, b: Significance between Group 1 Acetal \& Group 3 Karadent, c: Significance between Group 2 PEEK \& Group 3 Karadent

*: significance between Thermo versus control.

\section{DISCUSSION}

Based on the result attained in this study, retention forces differed significantly between the three thermoplastic materials before thermocycling, however after thermocycling these differences were statistically insignificant between the three materials. Hence, the null hypothesis could only be partially accepted.

Since dental society currently emphasizes on physical appearance, the demand for esthetic dental restorations has been increased. (25) In this study three esthetic thermoplastic clasp materials (Acetal, Karadent ,Peek) have been chosen to carry out this study as, these chosen thermoplastic resins, are widely used today in removable prostheses.
Maxillary first premolar teeth have been chosen as testing model for the following reasons; the sound first premolars could be easily obtained as several cases of orthodontic treatment include bilateral bicuspid extraction, the position of the upper first premolar in the esthetic zone that demand using of esthetic clasp for removable partial dentures. The use of natural teeth to test the retention force seemed to be closer to the oral condition, because the use of metal abutment tooth produces much greater friction to the abutment tooth surface, thereby increasing the retention. ${ }^{(43,44)}$ Moreover, two testing models were used with alternating testing the retentive forces of each group on each abutment tooth, to eliminate the factor of mutual abutment tooth wear 
or clasp material so that the retentive force could be measured more accurately.

Most of the studies used Aker clasp design to determine the retentive force of RPD..$^{(15,45,46)}$ The preformed wax pattern for Aker clasp was used to facilitate the standardization of the shape and thickness of clasps and to eliminate the factors that may affect the flexibility and also to eliminate manual variations ${ }^{(46-49)}$.

Clasp type influenced the increase in the retentive force of the clasp. However removable partial denture retention should be checked under wet conditions, especially for human enamel and porcelain to be clinically relevant ${ }^{\cdot(47,48)}$

The use of CAD/CAM technology for clasp wax pattern duplication allowed fully digital workflow that have the advantage over manual duplication and increased the ability to reproduce the same clasp assembly for all groups. ${ }^{(41)}$

Thermoplastic resin clasps used in the study were $1.5 \mathrm{~mm}$ in thickness and designed to engage a deeper undercut of $0.5 \mathrm{~mm}(0.02 \mathrm{inch})$ in order to obtain clinically acceptable retention and provide adequate stiffness; this is due to the relatively low rigidity of the thermoplastic resin ${ }^{(24,27,47,49)}$. Moreover the 0.5 $\mathrm{mm}$ undercut was chosen to simulate the situations where clasps should be positioned near to the gingival margin, where undercut needs to be deeper, thereby producing a more esthetic result. ${ }^{(44)}$

The holder sprue was placed at the saddle area distal to the clasp assembly as a pull-out location, this may be due to that the distal pull-out location had a significant effect on the clasp retentive force and it gave greater retention forces as compared to other locations of holder (ring on the rest, wax arising from two rests). The dislodgement of the clasp with the location of (loop on the saddle) resulted in a force that was not directed vertically along the path of draw. This pattern of dislodging forces mimics the direction of the forces acting on RPD in the patient mouth. ${ }^{(50)}$
The differences observed in the retention forces prior to thermo-cycling are probably due to the different modulus of elasticity of the materials. (Elastic modulus; 2.4 GPa for Acetal and 4.0 GPa for Peek) Thus, the greater modulus of elasticity of the material means less flexibility and greater retention force toward the Peek clasp group. ${ }^{(47,51)}$

The esthetic resin clasps-showed a decreased retention values when exposed to thermo- cycling (2000 cycle) between $\left(5^{\circ} \mathrm{C}-55^{\circ} \mathrm{C}\right) 30$ seconds. A decline in the retention force might be explained by an occurring material fatigue of the clasps associated with multiple deflections occurring during the process of thermo cycling. ${ }^{(52)}$

However the difference in the percentage of the change of the retentive forces between the groups was significant, with the least percentage of changes for the acetal groups $(-51.42,-46.22)$, this may also additionally be due to the fact that the more flexibility of Acetal clasps led to a lower retention and enabled less deformation of the clasp. This result agreed with a previous study stated that the retentive force of acetal resin clasps did not decrease over the cycling periods that would be attributed to the resilient nature of acetal resin. ${ }^{(53)}$

Limitations of this study include that the test was performed in a rigid system. Due to the presence of periodontal ligament, which allows physiological mobility of natural teeth, the results under clinical conditions may not be the same.

In the oral cavity, there are usually different insertion and removal paths, since obtaining truly effective guide planes is conditioned by anatomical aspects. In addition, the patients can change the path used to move the denture during each insertion and/ or removal cycle, thereby generating a higher load on the tooth, thus causing a permanent clasp defect in a short period of time. ${ }^{(54)}$ Compared to actual clinical use, these factors may have increased the retentive force values for the test. Therefore, more studies are needed, in conditions closer to clinical situations. 


\section{CONCLUSION}

Within the limitations of this study, it was found that the thermoplastic resin clasps showed a decreased retention when exposed to thermocycling $(2000$ cycle $)$ between $\left(5^{\circ} \mathrm{C}-55^{\circ} \mathrm{C}\right) 30$ seconds with significantly lower percentage of change for the Acetal than Peek and karadent esthetic clasp materials. Artificial aging led to a significant decline in retention force for PEEK-clasp material. This may recommend the use of acetal thermoplastic resin materials as esthetic clasps. However, further studies are needed, in conditions closer to clinical situations.

\section{Conflict of interest}

The current study exhibited author self-funding, without any conflict of interest.

\section{REFERENCES}

1. Bezzon O. L., Mattos M.G.C. and Ribero R. F.: Surveying removable partial denture: The importance of guiding planes and path of insertion for stability. J Prosthet Dent 1997; 78: 412-418.

2. Sailer I, Makarov NA, Thoma DS and Zwahlen M and Pjetursson BE. Allceramic or metal-ceramic toothsupported fixed dental prostheses (FDPs)? A systematic review of the survival and complication rates. Part I: Single crowns . Dent Mater. 2015; 31(6):603- 623.

3. Pommer B, Hingsammer L, Haas R, Mailath-Pokorny G, Busenlechner D and Watzek G, . Denture-Related Biomechanical Factors for Fixed Partial Dentures Retained on Short Dental Implants. Int J Prosthodont. 2015; 28(4):412-414.

4. Reddy JC, Chintapatla SB, Srikakula NK, Juturu RKR, Paidi SK and Tedlapu SK, . Comparison of Retention of Clasps Made of Different Materials Using ThreeDimensional Finite Element Analysis. J Clin Diagn Res. 2016; 10 (5): 13-16.

5. Vallittu PK, Kokkonen M. Deflection fatigue of cobaltchromium, titanium, and gold alloy cast denture clasp. J Prosthet Dent. 1974; (4):412-419.

6. Bergman B, Hugoson A, Olsson CO. A 25 year longitudinal study ofpatients treated with removable partial dentures. J Oral Rehabil 1995; 22:595-599.
7. Bates JF. The mechanical properties of the cobaltchromium alloys andtheir relation to partial denture design. Br Dent J 1965; 119:389-396.

8. Morris H, Farah JW, Craig RG, Hood JA. Stress distribution within circumferential clasp arms. J Oral Rehabil 1976; 3:387-394.

9. Frank RP, Nicolls JI. A study of the flexibility of wrought wire clasps.J Prosthet Dent 1981; 45:259-267.

10. Ghani F, Mahood M. A laboratory examination of the behaviour of cast cobalt-chromium clasps. J Oral Rehabil $1990 ; 17: 229-237$.

11. Snyder HA, Duncanson MG Jr. The effect of clasp form on permanent deformation. Int J Prosthodont 1992; 5:345350 .

12. Vallittu PK, Miettinen T. Duration of inductionmelting of cobalt-chromiumalloy and its effect on resistance to deflection fatigue of cast denture clasps.J Prosthet Dent 1996;75: 332-336.

13. VandenBrink JP, Wolfaardt JF, Faulkner MG. A comparison of various removable partial denture clasp materials and fabrication procedure forplacing clasps on canine and premolar teeth. J Prosthet Dent 1993; 70:180-8.

14. Firtell DN. Effect of clasp design upon retention removable partial dentures. J Prosthet Dent 1968; 20: 43-52.

15. Ahmad I, Sherriff M, Waters NE. The effect of reducing the number of clasps on removable partial denture retention. $\mathrm{J}$ Prosthet Dent 1992; 68:928-33.

16. Marei M. Measurement (in vitro) of the amount of force required to dislodge specific clasps from different depths of undercut. J Prosthet Dent 1995;74:258-63.

17. Bridgeman JT, Marker VA, Hummel SK, Benson BW, Pace LL. Comparisonof titanium and cobalt-chromium removable partial denture clasps. J ProsthetDent 1997; 78:187-93.

18. Kotake M, Wakabayashi N, Ai M, Yoneyama T, Hamanaka H. Fatigueresistance of titanium-nickel alloy cast clasps. Int J Prosthodont 1997; 10 :547-552.

19. Rodrigues RC, Ribeiro RF, deMattosMla G, Bezzon OL. Comparative studyof circumferential clasp retention force for titanium and cobalt-chromiumremovable partial dentures. J Prosthet Dent 2002; 88:290-296.

20. Moreno de Delgado M, Garcia LT, Rudd KD. Camouflaging partial denture clasps. J Prosthet Dent 1986; 55:656-60. 
21. Pardo-Mindan S, Ruiz-Villandiego JC. A flexible lingual clasp as an esthetic alternative: a clinical report. J Prosthet Dent1993; 69:245-24 6.

22. Firtell DN, Jacobson TE. Removable partial dentures with rotational paths of insertion: problem analysis. J Prosthet Dent 1983; 50:8-15.

23. Beaumont Jr AJ. An overview of esthetics with removable partial dentures. Quintessence Int. 2002; 33 (10):747-755.

24. Arda T, Arikan A. An in vitro comparison of retentive force and deformation of acetal resin and cobalt-chromium clasps. J Prosthet Dent. 2005; 94 (3):267-274.

25. Chu C, Chow T. Esthetic designs of removable partial dentures. Gen Dent. 2003;51 (4):322-324.

26. Fitton JS, Davies EH, Howlett JA, Pearson GJ. The physical properties of a polyacetal denture resin. Clin Mater 1994; 17:125-9.

27. Sadek S, Dehis W, Hassan H. Comparative Study Clarifying the Most Suitable Material to Be Used as Partial Denture Clasps. Open Access Maced J Med Sci]. 2018; 6: 1111-1119

28. Kurtz SM, Devine JN. PEEK biomaterials in trauma, orthopedic, and spinal implants. Biomaterials 2007; 28: 4845-69.

29. Toth JM, Wang M, Estes BT, Scifert JL, Seim 3rd HB, Turner AS. Polyetheretherketone as a biomaterial for spinal applications. Biomaterials 2006; 27 : 324-34.

30. Abd El Hameed HM and Mohamed EH . Bond strength of hard and soft relining materials to thermoplastic monomer free microcrystalline polymer (In-vitro comparative study). E.D.J. 2018; 64 (4):3559-3566

31. Palmer DS, Barco MT, Billy EJ. Temperature extremes produced orally by hot and cold liquids.J Prosthet Dent. 1987;66 : 1336-1339.

32. Longman CM, Pearson CJ. Variation in temperature of the oral cavity during the imbibition of hot and cold fluids [specialissue]. J Dent Res. 1984; 63 : 521-526

33. Boehm RF. Thermal environment of teeth during openmouth respiration. J Dent Res.1972; 51 (1):75-78.

34. Gale MS, Darvell BW. Thermal cycling procedures for laboratory testing of dental restorations. J Dent. 1999; 27(2):89-99.

35. Lira AF, Consani RL, Mesquita MF, Nóbilo MA, Henriques
GE. Effect of tooth brushing, chemical disinfection and thermos-cycling procedures on the surface microroughness of denture base acrylic resins. Gerodontology. 2012; 29(2):e891-e897.

36. Göhring TN, Gallo L, Lüthy H. Effect of water storage, thermos-cycling, the incorporation and site of placement of glass-fibers on the flexural strength of veneering composite. Dent Mater. 2005; 21 (8):761-772.

37. Machado AL, Bochio BC, Wady AF, Jorge JH, Canevarolo SV Jr, Vergani CE. Impact strength of denture base and reline acrylic resins: an in vitro study. J Dent Biomech. 2012; 3: 1758736012459535 . doi: 10.1177/1758736012459535.

38. Takahashi Y, Hamanaka I, Shimizu H. Effect of thermal shock on mechanical properties of injection-molded thermoplastic denture base resins. Acta Odontol Scand. 2012;70 (4): 297-302.

39. El- Segai AA, Abbas M. Retention and fatigue resistance of peek and acetal thermoplastic resin clasps E.D.J.;2018 Vol. 64:4019-4025

40. Mayinger F, Micovic D, Schleich A, Roos M, Eichberger $M$ and Stawarczyk B. Retention force of polyetheretherketone and cobalt-chrome-molybdenum removable dental prosthesis clasps after artificial aging Clin Oral Invest 2021; 25:3141-3149

41. Abd-Elrahman IA, Helal MA, Saqar HM and Abbas M .Evaluation of Fatigue Resistance of Acetal Resin and Cobalt-Chromium Removable Partial Denture Clasps. An In-vitro Study: Part 1. J of Dent and Oral Care Med 2016; 2(3): $1-6$

42. Enas Elhamy Negm, DDM , Faten Ahmed Aboutaleb, $\mathrm{PhD}$, \& Ahmed M. Alam-Eldein. Virtual Evaluation of the Accuracy of Fit and Trueness in Maxillary Poly (etheretherketone) Removable Partial Denture Frameworks Fabricated by Direct and Indirect CAD/CAM Techniques: Journal of Prosthodontics 28 (2019) 804-810.

43. Raghavendra J, Jasheel A, Sanjna N. Comparative evaluation of retention force and porosity for titanium and cobalt-chromium clasp assemblies' an in vitro study. World Appl Sci J 2014; 30:757-761.

44. Soo S, Leung T. Hidden clasps versus C clasps and I bars: A comparison of retention. J Prosthet Dent 1996; 75:622-625.

45. Ahmad I, Waters NE. Value of guide planes in partial denture retention. J Dent 1992; 20:59-64. 
46. Kim D, Park C, Yi Y, Cho L. Comparison of cast Ti-Ni alloy clasp retention with conventional removable partial denture clasps. J Prosthet Dent 2004; 91:374-382

47. Tannous F, Steiner M, Shahin R, Kern M. Retentive forces, and fatigue resistance of thermoplastic resin clasps. Dent Mater 2012; 28:273-278

48. Sato Y, Abe Y, Yuasa Y, Akagawa Y. Effect of friction coefficient on Akers clasp retention. J Prosthet Dent 1997; $78: 22-7$

49. Osadah, Shimpo h, Hayakawat, ohkubo c.Influence of thickness and undercut of thermoplastic resin clasps on retentive force. Dental Materials Journal 2013; 32(3): 381-389

50. Mourshed B, Al-Sabri FA, Qaed NA,Alaizari N, AlShamiri HM, Alfaqih A. Effect of clasp type and pullout location on clasp retention in different environment: In vitro study. Eur J Dent 2017;11:216-220.
51. Peng TY, Ogawa Y, Akebono H, Iwaguro S, Sugeta A, Shimoe S. Finite-element analysis and optimization of the mechanical properties of polyetheretherketone (PEEK) clasps for removable partial dentures. J Prosthodont Res 2019; 64:250-256

52. Helal MA, Baraka OA, Sanad ME, Al-Khiary Y, Ludwig $\mathrm{K}$, et al. Effect of clasp design on retention at different intervals using different abutment materials and in a simulated oral condition. J Prosthodont 2014;23: 140-5.

53. Meenakshi A, Gupta R, Bharti V, Sriramaprabu G, Prabhakar R. An Evaluation of Retentive Ability and Deformation of Acetal Resin and Cobalt Chromium Clasps. JCDR 2016;10: ZC37-41.

54. Bezzon OL, Mattos MGC, Ribeiro RF. Surveying removable partial dentures: the importance of guiding planes and path of insertion for stability. J Prosthet Dent 1997;78:412-418. 